\title{
Efforts to Reverse the Trend of Enrollment Decline in Computer Science Programs
}

\author{
Azad Ali and Charles Shubra \\ Indiana University of Pennsylvania, Indiana, PA, USA
}

azad.ali@iup.edu; Charles.Shubra@iup.edu

\begin{abstract}
Enrollment in computer science programs has been facing a steady decline for a number of years. Although more recent trend has shown a slight upward trend in enrollment, but the number of admitted students into computer science programs falls far short of what they have been before and in meeting employment demands. Numerous reasons have contributed to this decline and various steps have been taken by departments to counter this decline and to bring more students into their programs.

This paper examines steps taken to understand the causes and improvements to the availability of computer science graduates. Specifically, the Computer Science (COSC) program at Indiana University of Pennsylvania (IUP) has been proactively taking different steps in order to attract more students into their program and to improve retention among their enrolled students. The result of these efforts has been mixed and it is helpful to analyze these factors and delve into some aspects of the program to understand the extent of the steps taken so far. Thus the experience of the computer science program at IUP and their efforts to reverse enrollment decline is discussed in this paper.
\end{abstract}

Keywords: Computer Science Enrollment, enrollment decline in computer science programs, technology programs and enrollment

\section{Introduction}

Since the turn of the century, there has been a barrage of reports and statistics that point to one fact regarding enrollment in technology related programs: there is a sharp decline of enrollment in computer related courses and programs. This trend is not limited to computer science programs, but extends to all technology centric programs. Computer science programs in particular are one of the hardest hit programs that faced this sharp decline in enrollment (Ali, 2009; Benokraitis, Bizot, Brown, \& Martens, 2009; Dean, 2007; Zweben, 2009).

Recent years have shown some progress regarding increasing enrollment in these technology pro-

Material published as part of this publication, either on-line or in print, is copyrighted by the Informing Science Institute. Permission to make digital or paper copy of part or all of these works for personal or classroom use is granted without fee provided that the copies are not made or distributed for profit or commercial advantage AND that copies 1) bear this notice in full and 2) give the full citation on the first page. It is permissible to abstract these works so long as credit is given. To copy in all other cases or to republish or to post on a server or to redistribute to lists requires specific permission and payment of a fee. Contact 0HPublisher@InformingScience.org to request redistribution permission. grams, but a determination is yet to be made whether this slight upward trend represents a turn-around in enrollment or not (Markoff, 2009; Slonim, Scully \& Mcallister, 2008). Among these programs that witnessed some recent increase in their enrollment is the computer science program (COSC) at Indiana University of Pennsylvania (IUP). This department made numerous adjustments to curriculum, programs and 
degrees offered. The problem of enrollment is being addressed at the supply side by reaching out to high school students, secondary education technology teachers, guidance counselors and by establishing affiliations with other institutions. All of these efforts were (and are) aimed at reversing the trends of enrollment decline in their program. The experiences of this program along with the steps they have taken to reverse the trend of enrollment decline are illustrated in this paper.

The remainder of this paper is divided into five sections: The first section describes the low enrollment trends in computer science programs. It lists various statistics and employs charts that show this enrollment decline. The second section discusses possible reasons that led to this decline. The third section elaborates on steps that have been suggested to reverse this trend of enrollment decline among technology programs. The fourth section explains the steps and procedures that have been taken by the computer science program (COSC) at Indiana University of Pennsylvania (IUP) to reverse this trend. A summary and suggested future research is included at the end of this paper.

\section{Enrollment Decline - Numbers}

Different studies have been conducted and numerous statistics gathered to investigate this enrollment decline at the various Computer Science (CS) departments. All the studies and the statistics lead to one conclusion: There is a sharp decline in enrollment among computer science programs. The statistics differ by area of study, school and gender and sometimes categorize the numbers differently. However, despite these differences, the same statistics point to the grim reality of the enrollment decline among students enrolled in technology programs (Ali, 2009; Benokraitis et al., 2009; Dean, 2007; Vesgo, 2008; Zweben, 2009).

But to give one set of numbers to describe enrollment may not explain the whole picture of enrollment decline as there are numerous factors that affect these numbers. Thus, this section presents the data and analysis of enrollment from different viewpoints. It first describes the peak enrollment time(s) as they are often referred to when explaining enrollment numbers. Then it analyzes different charts that show the number of admitted students and graduates from CS programs and among women in particular. Later, it highlights enrollment numbers in the COSC program at IUP and makes additional notation on the general trend.

\section{Peak Enrollment Time}

When presenting trend data, it is accustomed to provide comparison numbers in terms of a peak period. In other words, in order to see the comparative numbers of any trend, statisticians tend to list the highest value of a particular trend and show comparative numbers as they relate to the trend being exhibited.

The trend of enrollment at CS programs may be better explained if they are compared to a similar peak (or highest) numbers. Most of the studies point to two particular periods for peak enrollment at CS programs: First, in the mid eighties and second to the beginning of this century (Zweben, 2009). The enrollment of women peaked only in the mid eighties (Esposito, 1998), no similar peak was experienced later on.

Different reasons explain both peak periods. The most notable reasons for the peak of the turn of this century are the Y2K issue, the surge of the Internet and the increase of e-commerce, the expanding use of PCs at home and at work, all of which contributed to the increase in computer related jobs (Markoff, 2009).

In order to simplify the analysis, this paper compares enrollment numbers to the most recent peak: The peak of the period following year 2000. The earlier peak period, may be helpful for comparison, but the most recent period provides more relevant and pertinent data. Additionally, it 
will be more manageable to show trends over several continuous years rather than going back to more than 20 years as the case if data from mid-eighties are used.

\section{Newly Admitted Students versus Degrees Awarded}

The number of students admitted into any department is only one aspect of the enrollment picture for a program. Students transferring out of CS programs after completing one or more semesters also have an effect. For example, some programs are notorious for having a high attrition (students dropping out of the program after starting it and prior to completing the intended degree requirements). Focusing on the dwindling number may not accurately describe the full picture of program enrollment. Thus, a more comprehensive view may be obtained by giving the number of admitted students into the program as compared to the number of students graduating in the CS major.

The computing research association (CRA) provides annual reports on enrollment in CS at doctoral granting institutions in the US (Zweben, 2009). The reports are titled the "Taulbee" report and are classified under different categories and show different trends. Vesgo (2008) took the 2008 Taulbee report and analyzed the number of admitted students enrolled into CS programs (Figure 1 below) and the number of graduating students since the fall of 1998 (Figure 2 below). Both Figures 1 and 2 show the total number of students overall as well the average number of students in each program in both categories (newly admitted as well as graduated students).

The enrollment chart in Figure 1 shows that number of admitted students into CS programs reached its peak in the fall of 2000 where programs had more than 100 students admitted per program. This is compared to less than 50 admitted in the fall of 2007 - a drop of more than $50 \%$ of newly admitted students. Figure 2 shows the number of CS graduates peaked in year 2003/2004 at about just above 70 graduates per year. The peak of newly enrolled in 2000 is consistent with the peak of graduates four years later (in 2003/2004) as it takes an average of four years for students to graduate from such a degree. Figure 2 shows a drop in the number of graduating CS students from a high of above 70 in the peak period to about 40 in year 2006/2007. Although recent numbers indicate a slight trend upward in the last year, it is too early to judge whether this upward trend is going to be sustained or not (Markoff, 2009; Slonim et al., 2008).

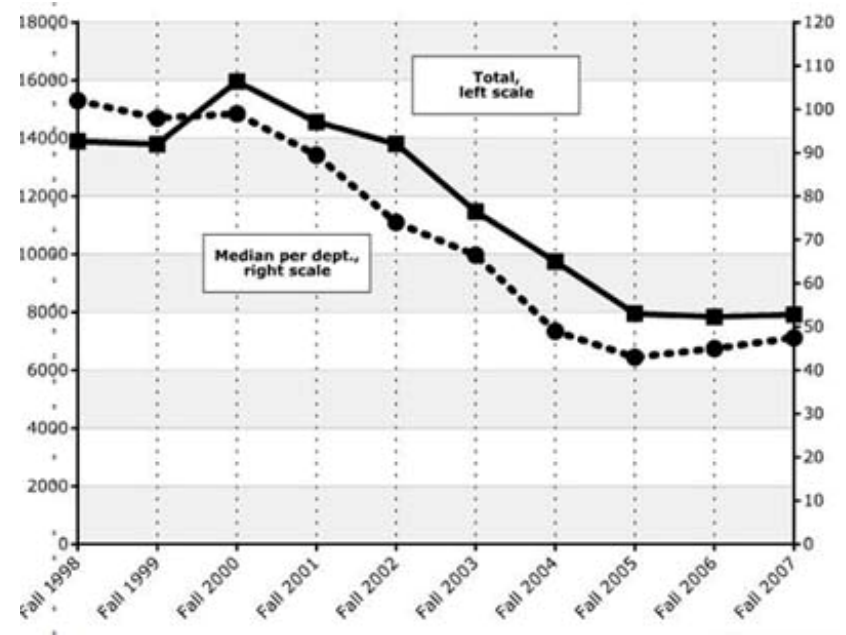

Figure 1 - Newly Declared CS Majors 


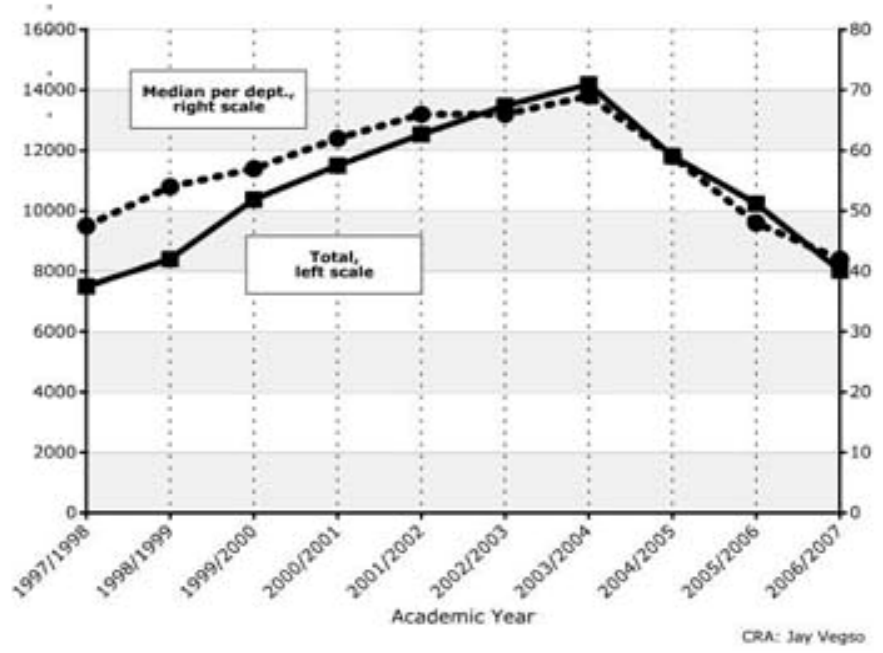

Figure 2 - CS Bachelor Degree Awarded

\section{Enrollment of Women at CS Programs}

The enrollment of women in CS programs has experienced a sharper decline than enrollment of men. A similar trend exists in retention and graduation rates. Lenox, Woratschek, and Davis (2008) for example noted that while enrollment dropped in technology courses by about $25 \%$, the decline of enrollment among women enrolled in technology programs dropped by $93 \%$ from the peak of women's enrollment in 1982. Cantwell (2002) reported that women represented only 18\% of the total number of students surveyed in the study were female. This supports the concern of the shortage of women in computer related programs.

Vilner and Zur (2006) sums up the problem of women's enrollment in technology related courses:

When you sit in a Computer Science lecture at any university in the western world, what are the chances that the person sitting next to you will be a woman? Furthermore, what are the chances that the lecturer will be a woman? And if we were to enter a Computer Science classroom in a high school, what percentage of the students would be female? Computer Science is possibly one of the few remaining disciplines that is almost entirely controlled by men in the university staff, and in which the percentage of female students is usually below $30 \%$. This phenomenon is prevalent throughout the western world. (p. 227)

Although fewer women are accepted into technology programs, the problem extends further into retention. Once they are accepted into the program, a higher percentage of women leave the program to pursue other majors. Vilner and Zur (2006) noted that the dropout rate of domestic female students at their institution in 2004 was $36 \%$, compared to $23.5 \%$ for domestic male students.

Having this kind of low female enrollment and then a higher rate of female attrition may lead to speculation that the cause of such low enrollment is the lack of academic ability among women to complete such courses. However, data does not support this notion. To the contrary, it seems that academic ability has little to do with women's attraction and retention to computer programs. A study conducted by Teague \& Roe (2008) noted the following about women's ability and admission into computer programs: 
Academic ability would seem to have little influence on women's attraction to and retention in programming courses. ... Women often perform well academically, yet perceive the programming environment as inhospitable, lacking social meaning and interaction which is incongruent with the real world. (p. 148)

Furthermore, the performance of women in technology programs does not seem to be below the performance of men in the same programs. A study conducted to measure performance of women in these programs found out that once women get admitted into a program they do fine and have about the same grade average as men (Vilner \& Zur, 2006).

\section{Enrollment Numbers at COSC}

Similar to other programs and to the national trend, the computer science (COSC) program at IUP had its' share of decline in enrollment. Figure 3 illustrates enrollment decline in the computer science program between the peak-time of year 2000 through year 2009. The figure displays both male and female students. Figure 3 shows a high of new admission of 114 male students and 28 female in year 2000-2001 while dropping to 44 male students and 2 female students in 20062007. The change in male enrollment represents a $61 \%$ loss from the peak of 2000-2001 year. The change in female enrollment represents a 93\% loss. Figure 4 shows the number of graduating students at the same program. Both charts follow the national trends where admission reached the peak at the turn of the century and continued to drop to less than $50 \%$ of their high. In the same time period, the graduating class reached its highest level in 2003, following the same logical pattern that a high number of admitted students in 2000 graduated approximately 4 years later.

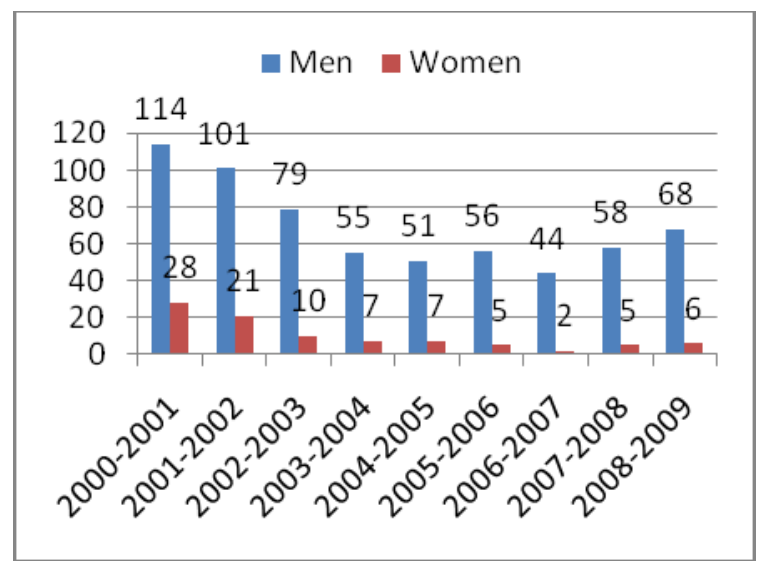

Figure 3

Newly Admitted COSC Students at IUP

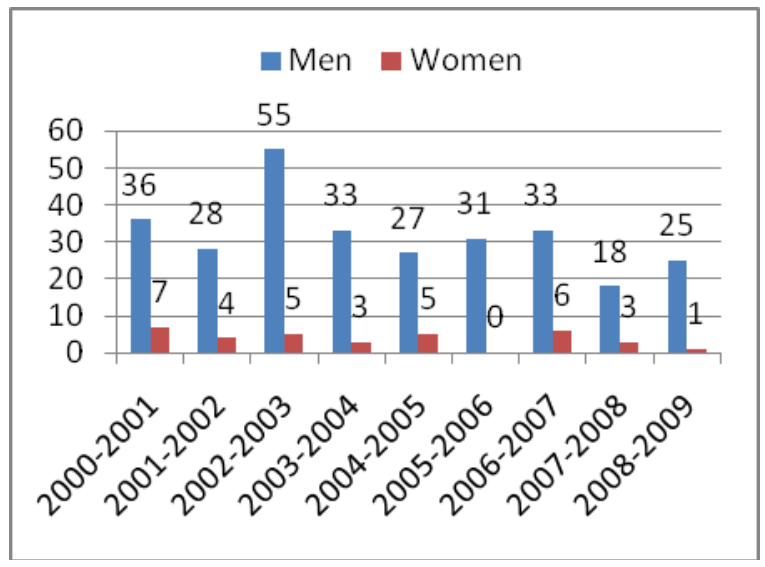

Figure 4

Number graduating COSC students at IUP

\section{More about Enrollment Numbers}

The charts listed above display only a partial view of the problem of enrollment decline in CS majors. Consistently data shows that student enrollment in CS programs is declining steadily. This does not parallel the national number of students enrolled at colleges and universities. According to the National Science Foundation (NSF), the percentage of students in CS programs compared to the total number of students in the same academic institutions fell from $5 \%$ to less $1 \%$ overall (Vesgo, 2008). This enrollment drop data among students who declare CS as a major field has many causes and reasons which made it the subject of analysis in numerous studies. 


\section{Enrollment Decline - Reasons}

Numerous studies have been conducted to address the phenomenon of decline in newly enrolled students and student retention among Computer Science majors. This decline was attributed to different reasons. This section discusses reasons which contributed to the decline of enrollment in computer science programs.

Lenox, Woratscheck and Davis (2008) conducted one such study. Their study attributed four common reasons for this enrollment decline: first, the image of technology courses as antisocial, second the cyclic nature of demand on technology professionals, third, the increase in the variety of technology related majors (like IT and MIS) and fourth the notion of outsourcing of technology jobs overseas.

A study conducted at Carnegie Mellon University (Blum \& Frieze, 2005) to address the reasons for dwindling number of women among CS majors found that stringent admission requirements and strong emphasis on mathematics may have contributed to the decline of women in CS programs. The same study addresses an issue that touches all students admitted into CS programs. Other studies point to additional reasons for the trend. For example, McDowell, Werner, Bullock, and Fernald (2006) point to the view that is generally perceived of CS majors that they are being antisocial, and that it may lead to a very competitive rather than collaborative course of study. A different group of researchers attribute this decline to the way that a first programming course is introduced and that projects in these courses are conducted in solitary rather than collaborative environment (Ali, Kohun, \& Wood, 2009; Carter \& Jenkins, 2002; Kelleher \& Pausch, 2005). Thus, a further study of the factors that contributed to this decline is warranted. The remainder of this section examines in more depth some of the reasons that contributed to the decline of enrollment among CS majors.

\section{First Programming Course}

It is well established among educators in the computer field that learning to program is a difficult task for the majority of students (Kelleher \& Pausch 2005). Different factors attributed to this difficulty including rigid syntax, unfamiliar structure and length of time spent to produce a simple output (Baldwin \& Kujilas, 2001; Cantwell, 2002; Sloan \& Troy, 2008).

Newly admitted students into CS programs learn their first programming language in a typical introductory course that selects one programming language and teaches the syntax of that language, problem solving, algorithm formation and the process of creating a working program. It seems that due to the difficulty experienced in learning to program, some students drop from the major all together instead of continuing and learning a different programming language or choosing an alternative technology track (Sloan \& Troy, 2008). To provide evidence of this notion, a study was conducted to investigate the effect of the first programming course on retention among CS students. The study estimated that at least $25 \%$ of students who drop their first computer course do so due to the difficulty in learning to program. This difficulty is experienced by all majors whether technology or non-technology majors (Carter \& Jenkins, 2002).

The issue of difficulty in the first programming is not limited to the selection of the programming language; instead it extends to the general notion of programming and to the method in which it is taught. Teague and Roe (2008) noted the following about programming:

Programming is often perceived as a solitary occupation, one which is conducted in a competitive, rather than collaborative environment. This is often reinforced at university where introductory programming subjects' assessment consists of individual assignments ... 
Programming is seen as a competitive occupation whose model student is the stereotypical 'geeky' young male, and this can lead initially to alienation, diminution of confidence and subsequent lack of interest for women. (p. 148)

\section{Outsourcing}

Outsourcing refers to shipping jobs abroad. According to this view, IT related jobs have been sent abroad to India, China and other countries where the cost of labor is lower (Rottman, 2006). The relationship between outsourcing of IT jobs to other counties and enrollment in CS programs may not seem direct and clearly evident. But understanding the cyclical trend of job market/job demand on college enrollment and the interactive effect of the two may help shed some light into this. Tony (2007) explained about this relationship between job availability and enrollment at CS programs:

The relationship between the professional industry and academic choices of students has generally been a two way feedback loop. The industry outlook encourages (or discourages for that matter) students to enter a certain field, while the number of resulting graduates shape the industry itself. The Dot Com Bubble of 1995-2001 nicely accounts for the last peak of interest in the Computer Science education. (p. 1)

At the same time, the loss of local jobs due to outsourcing may have a cyclical effect eventually contributing to lower enrollment. Outsourcing of IT jobs abroad leads to fewer jobs available locally, this in turn leads to less need for graduates in the market and fewer local job prospects. Employment opportunities are a primary consideration in choosing a major. To the extent that outsourcing causes the loss of local jobs it may also contribute to the impression that employment opportunities are limited. This can become a vicious circle. Figure 5 shows the cyclical nature of outsourcing and enrollment in CS programs.

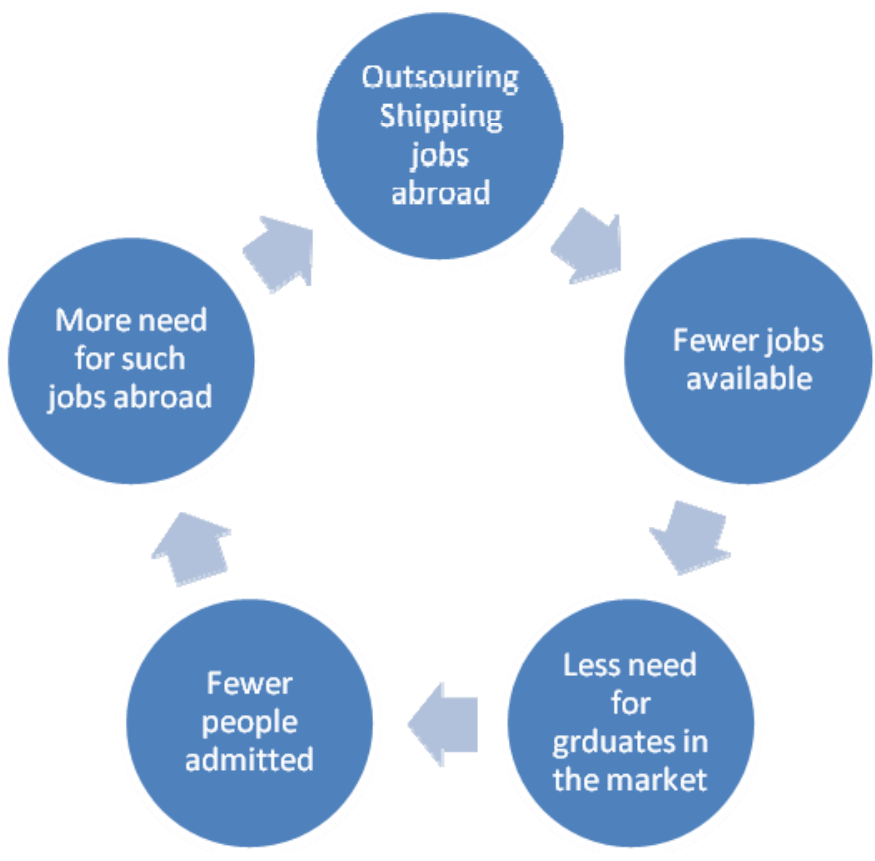

Figure 5 - Cyclical effect of Outsourcing 
Companies that attempt outsourcing may gain a number of benefits, but at the same time outsourcing may cost more than it gains. The advantages of outsourcing for companies may include any of the following: cheaper labor, lower operating cost, lower labor training cost, increase productivity, and allowing focus on core business. However, the disadvantages of outsourcing may include employees feeling a threat of job loss, loss of control, security issues and lower work quality.

Lowe (2002) noted the following about outsourcing of IT jobs:

For example, my company outsources its IT services (help desk, computer support and maintenance), and we pay significantly less than we'd pay for a fulltime IT person to give us the same level of support. We also outsource our bookkeeping and office administration, with similar savings. As we grow, we'll continue to reevaluate these decisions--it may be that the business case for the IT outsourcing remains good as we grow but that we might eventually hire someone to offload other work from our current people, and since we would be paying them anyway, we could get them to do the bookkeeping as well.

\section{Cyclical Downturn}

This idea comes from cyclical demand on products or supplies. At times, the demand for certain product increases while at others the demand decreases. For example, accounting majors faced cyclical downturn when computer applications in accounting increased thus rendered the old style of teaching manual accounting obsolete. Vesgo (2008) noted about the cyclical downturn for CS enrollment:

It is important to note that a steep drop in degree production among CS departments has happened before. According to NSF, between 1980 and 1986 undergraduate CS production nearly quadrupled to more than 42,000 degrees. This period was followed by a swift decline and leveling off during the 1990 s, with several years in which the number of degrees granted hovered around 25,000. During the late 1990s, CS degree production again surged to more than 57,000 in 2004. In light of the economic downturn and slow job growth during the early 2000s, the current decline in CS degree production was foreseeable. (p. 1)

\section{Diminishing Visibility}

The number of programs that offer technology related degrees is increasing at a rapid rate. The amount of technology coverage is increasing in related disciplines. For example, consider the increased use of technology in colleges of education. Around the turn of the century, three curriculum standards existed: CS2001, IS2002, and CE2001. That number increased to five with the addition of SE2004 and IT2005. (Computing curricula 2005 the overview report, 2005). The newer fields have also incorporated into their standard curriculum topics aligned with developments and application of new technologies into a widening range of applications. There is now a standard curriculum for the newly created Information Technology Volume (Computing Curricula Information Technology Volume, 2007) that overlaps in many areas with a traditional computer science program.

This issue extends further when it takes into consideration the many other computers related programs being initiated. The online degrees, growth in two year associate degrees, technical schools and the numerous other adjustments organizations make to offer degrees and certificates under different names cloud the market of computer education and eventually diminish the visibility of existing programs. 


\section{Suggested Remedies}

Numerous studies have been conducted that suggest remedies for the problem of enrollment decline in CS programs. At the same time, different universities adopted policies and procedures to address the difficulty of attracting and retaining students in CS programs.

Dean (2007) reported that Carnegie Mellon University moved away from emphasizing programming proficiency and now look for applicants who are high overall achievers with broad interests, diverse perspectives and potential future leaders. According to the same report, these changes increased the percentage of women in the CS program as well as increasing the overall number of students admitted into the program.

A study conducted by Mahmoud (2005) drew a brighter outlook for enrollment at CS programs and predicted a surge in the number of students majoring in the CS major in the near future. The same study suggested that CS departments attempt to meet today's information technology (IT) landscape through the following steps:

- Offer multidisciplinary and cross disciplinary programs

- Fix the computer science image

- Move toward a bachelor of arts degree

- Increase women's enrollment in CS

- Train high school computer science teachers

- Make CS courses fun

The suggestions are numerous. The remainder of this section explains in more depth suggestions to deal with the issue of enrollment decline at CS majors.

\section{Beginner Programming language}

Because of the difficulty of learning to program and the subsequent problems this difficulty may create, a new group of programming languages have emerged to address this issue. This group of programming languages is termed "Beginner programming languages" (Dann, Cooper, \& Pausch, 2006). The purpose of this group of languages is to make it easier to learn the concepts and methods of programming by providing visual and interactive learning environments. Among the leading languages in this group is a language called Alice - developed by Carnegie Mellon University through funding provided by the National Science Foundation.

Alice has different characteristics that make it suitable to be taught as a first programming language. Adams (2008) noted the following advantages of using Alice in introductory programming courses:

The allure of 3D graphics:

It is difficult to overstate the visual appeal of 3D animations, especially to today's visually-oriented students. When your program works, you feel euphoric! But even when you make a mistake (a logic error), the results are often comical, producing laughter instead of frustration.

The Alice IDE:

Alice includes a drag-and-drop integrated development environment (IDE) that eliminates syntax errors. The IDE eliminates all of the missing semicolons, curly braces, quotation marks, misspelled keywords or identifiers, and other syntax problems that bedevil CS1 students (P. 3). As the student drags-and-drops graphical elements source code is constructed and displayed. This source code can be in Alice syntax or Java-like syntax. The IDE also allows the choice of programming language constructs (e.g., loops and alternatives) from a toolbox. The student is 
never permitted to freely edit the code as is the case with most programming development environments. This again shields the student from making syntax errors, but allows them to become familiar with programming language constructs.

Dann, Copper, and Pausch (2006) expressed similar sentiment and explained that the use of Alice in a first programming course not only increased enrollment among CS majors but also increased retention and success rate among students transitioning to second year in CS programs.. Ali, Kohun, and Wood (2009) suggested that the design and syntax of Alice addresses all the noted factors that make it difficult to learn how to program. These factors are summarized in Table 1 below.

The choice of Alice for use in the first programming course is not without drawbacks or distracters. One question raised is "How will students perform in a second programming course if Alice is chosen over a more traditional language"? Further, Alice is not used in industry; instead it is an educational language that is aimed at teaching beginner or entry level concepts. Thus, there is no job in the industry that advertises a number of years of experience in Alice similar to what is required for working in other programming languages. Thus devoting an entire course to teach Alice may not improve marketability. A hybrid approach to teaching Alice for a portion of a course and then complementing it by teaching Java in the remainder of the semester may be more effective in reaching educational objectives while helping to retain students.

Table 1 - Alice addresses difficulty of learning to program

\begin{tabular}{|l|l|}
\multicolumn{1}{|c|}{$\begin{array}{c}\text { Reason for Difficulty in Learning to Pro- } \\
\text { gram }\end{array}$} & \multicolumn{1}{c|}{ How Addressed by Alice } \\
\hline Rigid Syntax and dealing with syntax errors & $\begin{array}{l}\text { Alice does not have syntax and no syntax er- } \\
\text { rors }\end{array}$ \\
\hline Unfamiliar Structure & $\begin{array}{l}\text { The structure in Alice is visual and easy to fol- } \\
\text { low }\end{array}$ \\
\hline Lack of visual output and immediate feedback & $\begin{array}{l}\text { Alice output is visual and provides instant } \\
\text { feedback }\end{array}$ \\
\hline Lack of motivation & \begin{tabular}{l} 
Alice examples are engaging and interesting \\
\hline Long time to develop simple program
\end{tabular} \\
\hline
\end{tabular}

\section{CS Degree Modification}

CS degree modification gives the impression that the program is kept up to date. Revising the content of a CS degree, introducing new courses, and changing program requirements - all mean that something is being done to the program of study to address issues with the program. Degree modification especially those that are done to accommodate market demand and technological changes results in bringing more students into the programs.

CS degree modifications that respond to market demand and job outlook most likely have a positive impact on enrollment among students. The market demand is crucial to the success of new programs. Academic programs are known to follow the foot-steps of the market demand. If the demand of the market increases, so does enrollment of specific programs. Yew (2008) used the word "Attractiveness" to refer to the demand on certain programs by students and noted: 
Most students consider job prospects a significant factor in their decisions to major in a field of study. Therefore, the student perception of job prospect associated with the degree is expected to be a major factor in determining the "attractiveness" of a program. (p. 5)

Ali and Farag (2009) noted a similar effect in choosing a program to respond to market demand. They proposed offering of a degree (minor) in information assurance to respond to current demand of the market and to offset the decline of other jobs availability.

\section{Accreditation and Recognition}

Getting accreditation from a recognized agency is a means of proving high standards for that department. Accreditation has long been recognized as a mean of maintaining the highest standards of professionalism (New Jersey State Association of Chiefs of Police, 2002). According to the U.S. Department of Education (2009) web site, "The goal of accreditation is to ensure that education provided by institutions of higher education meets acceptable levels of quality. Accreditation in the United States involves non-governmental entities as well as governmental agencies" (p. 1).

According to the Accreditation Board for Engineering and Technology (ABET, 2009), accreditation helps the institution through the following ways:

- Accreditation helps students and their parents choose quality college programs.

- Accreditation enables employers to recruit graduates they know are well-prepared.

- Accreditation is used by registration, licensure, and certification boards to screen applicants.

- Accreditation gives colleges and universities a structured mechanism to assess, evaluate, and improve the quality of their programs.

Numerous steps and procedures are utilized when acquiring accreditation. For example, criteria are published as to program content, program educational objectives are defined to meet the needs of constituents, program and course outcomes are defined and a mapping established to assure these outcomes contribute to the program educational objectives. Assessment and analysis procedures are closely reviewed to assure adherence to quality of the program according wellestablished set of guidelines. Furthermore, additional periodic reviews are conducted to assure the quality is maintained in the program and that procedures are put in place to measure quality.

Support by a nationally recognized agency has the potential to add more credibility to the program (Ali \& Farag, 2009). This kind of support will eventually bring more monetary support as well as bringing more students into the program.

\section{Efforts to Reverse the Trend}

This section outlines the experience of the computer science program (COSC) at Indiana University of Pennsylvania (IUP) and how their efforts resulted in reversing the downturn of enrollment trends in their program. This department has been working for a number of years to reverse this trend. It has partnered with other departments, introduced new programs and made a lot of changes to their existing programs. The remainder of this section elaborates on the efforts of the COSC at IUP.

\section{Increasing the Supply}

The department aggressively pursued an increase in the supply of students enrolling in the computer science program. This meant reaching out to all the sources of students: high schools, community colleges, undeclared majors or students considering a change of major and nontraditional students. The plan was to assure that the prospective students and their families had the 
best possible information upon which to base their selection of a major. Faculty participate in university sponsored Admission Expo's which bring students and their families to the university to learn about the various majors available. They participate in Science Day which is sponsored by the College of Natural Science and Mathematics and brings high school faculty and their students to campus to hear a number of short presentations centered on specific topics contained in the major (e.g., robotics, information assurance, and database). Faculty volunteer to attend career days at high schools to discuss the possible employment opportunities available upon completion of a COSC degree. The department has sponsored programming contests which bring high school students to campus to participate in programming and problem solving exercises. Faculty participate in ARIN sponsored the mentorship program which is a ten week three hours per week program to introduce students to the various topics in computer science with a hands on emphasis. The participation in the mentorship program has resulted in numerous students enrolling in the COSC program. COSC believes that economic conditions exist which favor IUP (lower tuition) over several of the universities with whom we compete for students.

COSC has reached out to community colleges with articulation agreements that establish course transfer policies for community college students wishing to enroll in COSC at IUP.

COSC is concerned with the identity or lack of a clear identity for computer science at the high school level. In the state of Pennsylvania, high school teachers are required to be certified by subject (e.g., Mathematics, Physical Education) to be allowed to teach that subject at the high school level. There is no certification specifically targeted to teach computer science. Currently, high school faculty members are certified through business education to teach technology subjects. While advanced placement courses exist which carry college credit for the first programming course, they suffer from all of the problems of the first programming course whether taught at the high school or the university level. Further, technology based curriculum include such courses as keyboarding and Microsoft Office applications. While important topics these are not computer science and may be sending the wrong message as to what computer science is.

\section{Efforts at Retention}

Because of small class sizes, students in COSC can and do receive individual attention from course faculty. Students have access to faculty through office hours. The computer science club provides tutorial sessions to aid struggling students. Students are given information about employment opportunities both while in school and upon graduation which provides motivation to complete the degree.

There are three tenure track female faculty members out of ten total faculty members. Female students have an opportunity to join and participate in "Women in Science" activities, research and scholarships.

\section{Accommodating New Programming Language Issue}

As a means of addressing the difficulty of non CS majors in learning how to program, COSC introduced a new course in Alice programming language into their program. The new course is a hybrid course which teaches Alice at the first half of the course and then bridges it to Java in the second part of the course. This course is seen initially as a non-majors course, but will be used for COSC majors who are seen to be at risk. Initial results have been positive.

\section{Programmatic Changes and new Degree}

The offerings of a department need to be under constant scrutiny to assure that the outcomes are being achieved, that the curriculum is updated to reflect the rapid advances in technology and that graduates are well prepared for graduate school and/or the current job market. The philosophy of 
the COSC department is to provide students with a firm foundation of concepts; vocabulary and theory in each course, but to then apply this foundation using the most appropriate technologies currently being employed. This philosophy results in graduates who "hit the ground running" i.e., are prepared on day one to be productive and who know how to keep pace with advances in technology.

To achieve these goals faculty must remain current with advances in technology and incorporate these in its course offerings. As new versions of languages become available and gain acceptance the course curriculum is updated. One extreme case is the number of updates to the Visual Basic course which has kept pace with the frequent nontrivial changes to the Visual Basic language provided by Microsoft. Languages do not provide the only source of updates as methodologies; paradigms and programming tools are also a source of advancement.

Further, the department must gage the current and future needs of its constituents in terms of job skills. The corporate advisory board, colloquium speakers and internship contacts all provide valuable input as to job trends, skills needed and existing opportunities. Having strong industrial relationships helps maintain an exceptional job placement record. When recruiting students for the program the job placement record is always of interest to the students and their families.

On a larger scale, COSC has initiated a new degree program. In 2002, COSC added a B.S. in Information Assurance to its existing degree offerings. All of the degrees require completion of a core of courses which emphasize software development skills with heavy emphasis on programming. Each degree then has a track which is a two to four course specialization that focuses on specific technologies and skills. The B.S. in IA was in response to the needs for information assurance professionals. This has been a very attractive offering for incoming students as thirty seven students are currently enrolled in this degree track. The B.S. in IA has lead to COSC being recognized as a Center of Academic Excellence in Information Assurance Education.

\section{ABET Accreditation and Degree Recognition}

Having your program recognized by an outside agency as being excellent is very useful as a recruiting tool. Such recognition provides visibility (through national web sites) and accessibility to grant programs for facilities, faculty research and student scholarships. The CAE-IA is one such recognition attained by COSC.

The department is currently undergoing ABET (Association of Business, Engineering and Technology) accreditation of its B.S. in Languages and Systems (B.S.in LAS) degree. The ABET process began with a modification of the curriculum to align with the ABET criteria. Assessment materials are being collected and a site visit is planned for Fall 2010. It is hoped that this will lead to an ABET Accredited program and the advantages of being recognized as an accredited program.

\section{Summary and Future Plan}

This paper explained about the trend of enrollment decline among technology majors in general and among computer science programs in particular. It elaborated on the experience of the computer science program (COSC) at Indiana University of Pennsylvania (IUP). It discussed the steps that have been taken by this department which led to reverse this trend of enrollment decline and to admit more students into their program than has been admitted in each of the last several years.

The paper began by giving numbers and stats that showed this trend of decline. It followed by analyzing the factors that led to the decline of enrollment. It then introduced steps that have been taken to deal with this issue of enrollment decline among students enrolled in technology program. Last, the paper elaborated on the experience of the COSC program at IUP which were suc- 
cessful in reversing this trend of enrollment decline and as a result larger number of students has been admitted into the program than have been in the last several years.

While writing this paper, several details were omitted to accommodate the limitation of number of pages and also to meet the deadline for completing this paper. One of the major issues that needs to be addressed in more detail is that of retention. Admitting more students into a computer science degree program is a good step forward. However, completing a computer science degree requires that students maintain an interest in computing which caused them to enroll in the first place and that they make steady progress in meeting degree requirements. Thus these topics will be the subject of discussion of the authors of this paper in future research.

\section{References}

ABET. (2009). Accreditation assures quality. Retrieved December 9, 2009 from http://www.abet.org/the basics.shtml

Adams, J. (2008). Alice in action: Computing through animation. Boston, Massachusetts: Course Technology.

Ali, A. (2009) Successful efforts in recruiting women into technology courses - A case study. Issues in Information System, X(1), 225-231.

Ali, A., Kohun, F., \& Wood, D. (2009) Selecting a first programming language to teach prospective teachers - Case Examples from two programs. Issues in Information System, X(2), 128-137.

Ali, A., \& Farag, W. (2009). Introducing a new concentration in information assurance. Issues in Information Systems, C(2), 185-192.

Baldwin, L. P., \& Kuljis, J. (2001). Learning programming using program visualization techniques. Proceedings of the 34th Hawaii International Conference on System Sciences - 2001. Retrieved April 17, 2008 from IEEE Computer Society Digital Library http://www.computer.org/portal/

Benokraitis, V., Bizot, B., Brown, R., \& Martens, J. (2009). Reasons for CS decline: Preliminary evidence. Journal of Computing Sciences in Colleges, 24(3), 161-162. Retrieved April 24, 2009 from ACM digital library http://www.acm.org/dl

Blum, L., \& Frieze, C. (2005). The evolving culture of computing. Frontiers: A Journal of Women Studies, 26(1), 110-125. Retrieved June 11, 2008, from Academic Search Complete database.

Cantwell B. (2002). A study of factors promoting success in computer science including gender differences. Computer Science Education, 12(1/2), 141. Retrieved June 11, 2008, from Academic Search complete database.

Carter, J., \& Jenkins, T. (2002). Gender differences in programming? Proceedings of the 7th Annual Conference on Innovation and Technology in Computer Science Education. Retrieved April 15, 2008 from ACM Digital Library http://www.acm.org/dl

Computing curricula 2005 the overview report. (2005). Retrieved October 2, 2006 from ACM Digital Library http://www.acm.org/dl

Computing Curricula Information Technology Volume (2007). Retrieved March 4, 2009 from ACM Digital Library http://www.sigite.org/

Dann, W., Copper, S., \& Pausch, R. (2006). Learning to program with Alice. Upper Saddle River, NJ: Prentice Hall.

Dean, C. (2007). Computer science takes steps to bring women to the fold. New York Times. Retrieved June 12, 2008, from Academic Search Complete database

Esposito, A. (1998). Steady decline in female computer majors is troubling. Retrieved April 29, 2009 from http://www.cs.ubc.ca/labs/swift/archives/esposito.html 
Kelleher, C., \& Pausch, R. (2005). Lowering the barriers to programming: A taxonomy of programming environment and languages for novice programmers. ACM Computing Surveys, 37(2), 83-137. Retrieved March 28, 2008 from ACM Digital Library http://www.acm.org/dl

Lenox, L. L., Woratschek, C. C., \& Davis, G. A. (2008). Exploring declining CS/IS/IT enrollments. Information Systems Education Journal, 6(44), 1-11.

Lowe, K. (2002). The pros and cons of outsourcing. Enterpenure. Retrieved December 8, 2009 from http://www.entrepreneur.com/humanresources/hiring/article49616.html

Mahmoud, Q. (2005). Revitalizing computer science education. Computer (May 2005), 100. Retrieved April 26, 2009 from IEEE Computer Society.

Markoff, J. (2009). Computer science programs make a comeback in enrollment. The New York Times. Retrieved April 27, 2009 from http://www.nytimes.com/2009/03/17/science/17comp.html?_r=1\&_r\&ref=science

McDowell, C., Werner, L., Bullock, H., \& Fernald, J. (2006). Pair programming improves student retention, confidence, and program quality. Communication of the ACM, 49(2), 90-95. Retrieved March 7, 2009 from ACM digital library http://www.acm.org/dl

New Jersey State Association of Chiefs of Police. (2002). New Jersey Association Law Enforcement Program. Retrieved March 1, 2009 from http://www.gtpd.org/Accred\%20overview.pdf

Rottman, J. W. (2006). Successfully outsourcing embedded software development. Computer (January 2006), Retrieved April 26, 2009 from IEEE Computer Society.

Sloan, R. H., \& Troy, P. (2008). CS 0.5: A better approach to introductory computer science for majors. Proceedings of the 39th SIGCSE Technical Symposium on Computer Science Education, 271-275.

Slonim, J., Scully, S., \& McAllister, M. (2008). Crossroad for Canadian CS enrollment. Communicationss of the $A C M, 51(10), 66-70$.

Teague, D., \& Roe, R. (2008). Collaborative learning - Towards a solution for novice programmers. Proceedings of the Tenth Conference on Australasian Computing Education - Volume 78, 147-153.

Tony (2007). Computer science enrollment trends. CompSci.ca Blog. Retrieved April 27, 2009 from http://compsci.ca/blog/computer-science-enrollment-trends

U.S. Department of Education. (2009). Accreditation in the United States. Retrieved December 9, 2009 from http://www.ed.gov/admins/finaid/accred/index.html

Vesgo, J. (2008). Enrollment and degree production at US CS departments drop further in 2006/2007. CRA Bulletin. Retrieved April 27, 2009 from http://www.cra.org/wp/index.php?p=139

Vilner, T., \& Zur, E. (2006).Once she makes it there: Gender differences in computer science study. ITICSE '06: Proceedings of the 11th annual SIGCSE Conference on Innovation and Technology in Computer Science Education. Retrieved March 6, 2009 from ACM digital library http://www.acm.org/dl

Yew, B. K. (2008). A perspective on a management information systems (MIS) program review. Journal of Information Technology Education, 7, 299-314. Retrieved from http://www.jite.org/documents/Vol7/JITEv7p299-314Yew366.pdf

Zweben, S. (2009). Computing degree and enrollment trends. Washington, DC Computing Research Association. 


\section{Biographies}

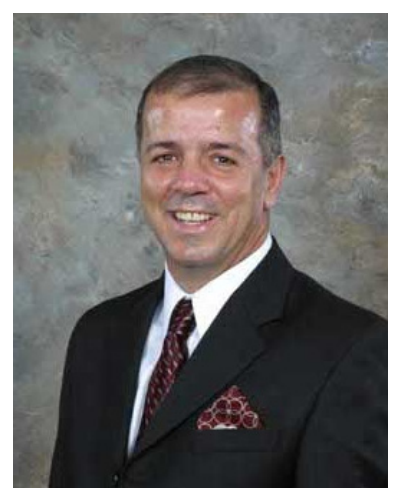

Azad Ali, D.Sc., Associate Professor of Technology Support and Training at Eberly College of Business - Indiana University of Pennsylvania has 28 years of combined experience in areas of financial and information systems. He holds a bachelor degree in Business Administration from the University of Baghdad, an M.B. A. from Indiana University of Pennsylvania, an M.P.A. from the University of Pittsburgh, and a Doctorate of Science in Communications and Information Systems from Robert Morris University. Dr. Ali's research interests include service learning projects, web design tools, dealing with isolation in doctoral programs, curriculum design and others.

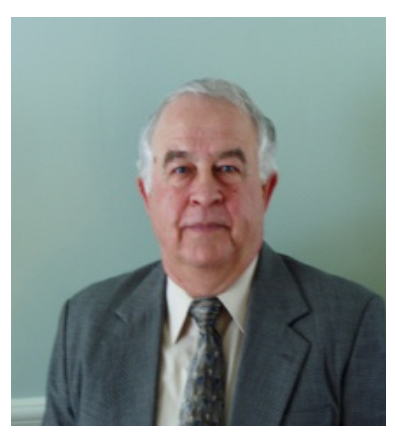

Charles Shubra, Ph.D in Computer Science, Chairman and Full Professor of Computer Science at Indiana University of Pennsylvania has over 40 years of teaching experience in software engineering, database management and programming languages. This is combined with industrial and consulting experience in information systems. He holds a B.S. degree in Mathematics from Indiana University of Pennsylvania, a M.S. degree in Computer Science from The Pennsylvania State University and a Ph.D. in Computer Science from The Ohio State University. Dr. Shubra's interests include information systems development, software engineering, database management systems, computer science education and academic-industrial relations to include internship programs. 